
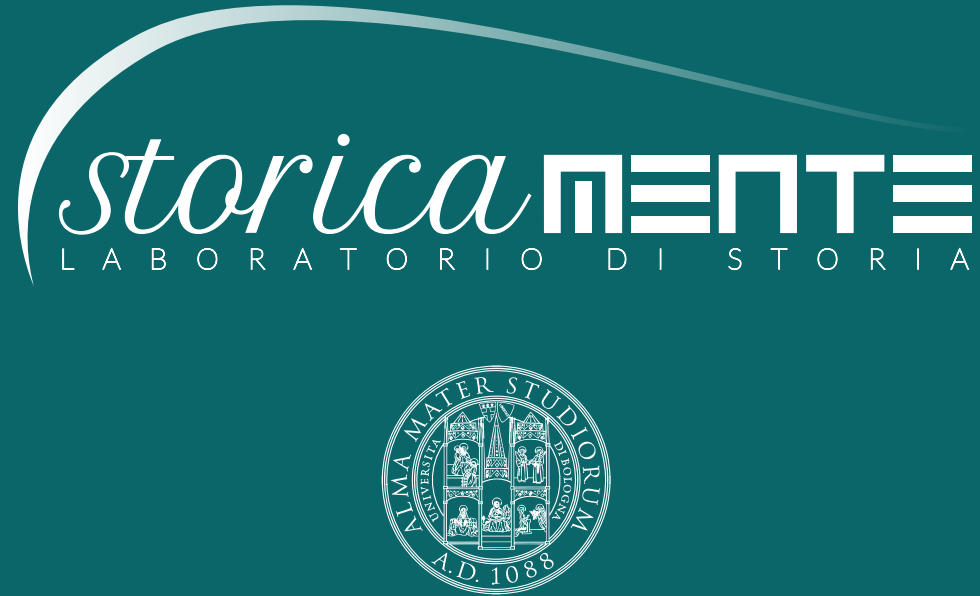

ALMA MATER STUDIORUM

Università di Bologna

Dipartimento di Storia Culture Civiltà

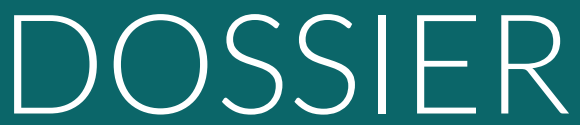

IMPERI: POLITICHE ED EREDITÀ NEL "LUNGO NOVECENTO" (ITALIA, PORTOGALLO, SPAGNA) 


\section{STORICAMENTE.ORG}

\section{Laboratorio di Storia}

\section{Albert Garcia-Balañà}

Migración y Milicia en la España trasatlántica del siglo XIX:

ange y caída del imperialismo popular

Numero 12 - 2016

ISSN: 1825-411X

Art. 2

pp. 1-24

DOI: $10.12977 /$ stor618

Editore: BraDypUS

Data di pubblicazione: 15/05/2016

Dossier: Imperialismi e retaggi postcoloniali in Italia, Portogallo, Spagna, a cura di Matteo Pasetti 


\title{
Migración y Milicia en la España trasatlántica del siglo XIX: auge y caída del imperialismo popular
}

\author{
ALBERT GARCIA-BALAÑÀ
}

Univ. Pompeu Fabra, Departament d'Humanitats

Barcelona, España

The article proposes an approach to the second Spanish imperial crisis, from 1898 onwards, from the observation of two phenomena longhaul until today just related by historians. Metropolitan migration to colonial destinations (Cuba, Puerto Rico, Spanish Africa...) and the formation of colonial militias, potential areas of social promotion and popular politicization. From this double perspective, the "end of Spanish empire" around 1900 emerges as the result of a complex combination of crises which influence each other. International crises, colonial crisis and metropolitan crisis with the Spanish colonies and its borders as a backdrop.

\section{Introducción}

En los últimos días de 1859 la ciudad de Barcelona reclutó, financió y despidió con entusiasmo a cuatro compañías armadas llamadas de "Voluntarios Catalanes" con destino al norte de África. Su objetivo era sumarse a la ofensiva militar que España había lanzado contra el Sulta- 
nato de Marruecos en octubre de aquel año en respuesta a incidentes fronterizos a las puertas de Ceuta, una de las plazas norteafricanas bajo soberanía española desde el siglo XVI. La llamada "Guerra de África" (Octubre de 1859 - Abril de 1860) fue el primer capítulo hacia el modesto dominio colonial español sobre parte de Marruecos, y también la primera demostración de la doble tutela, británica y francesa, que vigiló y acotó las ambiciones de Madrid durante las décadas siguientes. Las consecuencias territoriales de la victoria española en Tetuán en 1860 iban a resultar mínimas. Algo más relevante para el futuro resultaría la intervención española de las aduanas marroquíes en concepto de reparaciones de guerra, intervención compartida con Gran Bretaña, principal acreedora del Sultanato a raíz de esa misma guerra. Sin embargo, el mayor éxito de la Guerra de África tuvo lugar en el frente interior. Barcelona durante el invierno de 1859-1860 constituyó un buen ejemplo de ello. El entusiasmo bélico y los discursos de legitimación de la guerra alcanzaron a todos los grupos sociales en la ciudad, alumbrando una aparente unanimidad respecto de la campaña africana del gobierno monárquico del general Leopoldo O’Donnell, aprendiz del Napoleón III ultramarino. El medio millar de puestos de Voluntarios Catalanes, para civiles, se llenaron con mucha rapidez, y muchos de sus entusiastas publicistas aparecieron en la Barcelona más interclasista y políticamente radical, en el mundo de la oposición Demócrata o ya Republicana a los gobiernos de Isabel II [Garcia-Balañà 2002]. Incluso el corresponsal para el Times en la guerra marroquí, Frederick Hardman, pudo captar la complejidad y el poder de un patriotismo imperialista que así recibía a O'Donnell en África «with the band playing the Marcha Real» como despedía a los Voluntarios Catalanes «with Riego's hymn and other Liberal melodies» de muy vivo perfume revolucionario'.

La ciudad de Barcelona y una guerra de expansión en Marruecos regre-

1 Sobre la Guerra de África (1859-1860) en Barcelona y Cataluña: Garcia-Balañà 2002. La cita final en Hardman 1860, 53-54. 
saron a los grandes titulares de la vida española en el verano de 1909. Regresaron, sin embargo, con una atmósfera comunitaria muy distinta a la de 1859. En julio de 1909 no hubo batallones de voluntarios civiles en el puerto de Barcelona, y fue la movilización forzada de reservistas con destino Melilla, para combatir a las kabilas armadas del Rif marroquí, la chispa que hizo estallar la ciudad. El lunes 26 de julio Barcelona amaneció paralizada por una huelga general contra los embarques de hombres hacia Marruecos. Mediante las redes sindicales y las Republicanas la protesta alcanzó el hinterland barcelonés, la mayor región urbana e industrial de España (la provincia de Barcelona ya superaba el millón de habitantes en 1900, muy por delante de la de Madrid). Una ola de guerra social y de violencia material y simbólica se apoderó de la ciudad durante los días siguientes, hasta que la llegada de tropas del exterior pudo aplastar la rebelión el sábado 31 de julio. El balance de lo que la memoria patricia daría en llamar "Semana Trágica” de 1909 resultó revelador incluso para la Barcelona radicalizada de entresiglos: más de 100 civiles murieron durante los combates callejeros, al menos 52 iglesias y edificios religiosos fueron destruidos por los rebeldes, 6.000 metros cuadrados de adoquines fueron levantados para la construcción de barricadas, y más de 1.700 personas fueron juzgadas tras la represión por tribunales militares (que dictaron 17 penas de muerte, cinco ejecutadas). No hay duda de que la oposición a la guerra colonial fue uno entre varios y distintos factores de agravio popular que se mezclaron en la revolución barcelonesa [Ullman 1968; Balfour 1997, 123-131]. La cuestión, aquí, es por qué esta otra campaña militar de penetración en el Sultanato apelando a la defensa de la soberanía y el interés españoles ${ }^{2}$, que podía evocar pues la mayoritaria complicidad africanista del pasado, significó en 1909 el pistoletazo hacia la fractura social y comunitaria.

2 Sobre la campaña de 1909 en Marruecos y su contribución al establecimiento del Protectorado español en 1912: Balfour 2002, 23-70. 
¿Qué era lo que había cambiado radicalmente desde 1859? ¿El alcance del eclipse imperial español, y la evidente debilidad de la posición en Marruecos tras 1898 y tras la Conferencia de Algeciras (1906)? ¿O el tejido social y político de Barcelona y su región, y su proximidad o lejanía con respecto a las políticas gubernamentales? En verdad habían cambiado las consecuencias de las interferencias e influencias entre ambos procesos, interferencias constantes y cambiantes desde mitad de siglo. El significativo contraste entre 1859 y 1909 en Barcelona no puede ser explicado por la mera acumulación, durante dos generaciones, de episodios de subordinación internacional y crisis colonial en la España liberal. Tales episodios proliferaron a lo largo de este medio siglo, alimentados ante todo por la España caribeña aunque con repercusión en los territorios africanos de ambición hispana e incluso en el Pacífico español en retirada. Sin embargo, semejante inversión de lo que podríamos llamar "expectativas imperiales" de amplios grupos metropolitanos exige algún tipo de aproximación a cuáles podían ser los significados concretos de aquellas expectativas a la altura de 1859 . Una aproximación, también, a cómo dichos grupos fueron alterando tales expectativas con el transcurrir de aquellos episodios de crisis colonial y militarismo ultramarino, y con sus impactos metropolitanos. Una perspectiva, por consiguiente, que atienda a la transformación a la baja (o al abandono) de aquellas expectativas imperiales de amplio espectro social, en lugares como Barcelona y su región, para mejor comprender el eclipse imperial español del cambio de siglo.

La cronología de cualquier narrativa sobre esta deserción metropolitana y popular con respecto a las últimas expectativas imperiales españolas no debe focalizarse en 1898. La derrota final frente a los Estados Unidos en el Caribe y en el Mar de China no lo explica todo. El caso de Barcelona ofrece argumentos para una explicación más dilatada en el tiempo y más compleja en la acumulación y combinación de causas. En la primavera de 1869 sí regresaron los Voluntarios Catalanes a la escena barcelonesa, entonces con destino a lo que todavía nadie llamaba Pri- 
mera Guerra Cubana (1868-1878). Más de 3.500 Voluntarios Catalanes se alistaron y embarcaron hacia Cuba en 1869, más del 10\% de todas las fuerzas metropolitanas embarcadas hacia la isla según estimación del cónsul estadounidense en Barcelona. Aunque sus promotores pertenecían a la élite económica e institucional de la ciudad, la operación de alistamiento de civiles resultó un éxito inmediato (los Voluntarios triplicaron el número de soldados de leva para Ultramar asignado a la provincia de Barcelona en 1869) ${ }^{3}$. Incluso la prensa Republicana, partidaria de una respuesta no exclusivamente militar al levantamiento cubano, le dispensó su inicial aunque matizado apoyo. Un jovencísimo José Martí, desterrado en la Península en 1871, aludió en uno de sus artículos publicados en Sevilla a los «Voluntarios Catalanes republicanos», dando a entender la inicial simpatía del liberalismo metropolitano más interclasista y democratizador para con dicha miliciat. Una generación después, en la primavera de 1895, y ante una nueva insurrección cubana que pocos intuían más amenazadora que las anteriores, ningún batallón de Voluntarios Catalanes embarcaría en Barcelona dirección a La Habana. ¿Qué había cambiado pues, entre los años 1860s y los tempranos 1890s, con respecto a aquellas expectativas imperiales en espacios metropolitanos como la Barcelona más interclasista?

\section{Migraciones metropolitanas y expectativas imperiales popula- res durante el siglo XIX: interpretando el caso catalán}

Una notable diferencia puede rastrearse en uno de los motores que en

3 US National Archives and Records Administration, Despatches from US Consuls in Barcelona, Spain (1797-1906), T 121, Roll 6 (Jan. 41864 - Dec. 30 1869): carta del cónsul Perkins al Secretario de Estado Fish (Barcelona, 10 de Diciembre de 1869); sobre los Voluntarios Catalanes de 1869 hacia Cuba: Garcia-Balañà 1995, 94-102.

4 Ver José Martí, La Solución, publicado en «La Cuestión Cubana» (Sevilla), 26 de Abril de 1873, y que reproduce Paz Sánchez 2008, 147-161. 
1869 movió a muchos Voluntarios Catalanes a alistarse con destino Cuba: el motor de la emigración metropolitana hacia la sociedad colonial. «En la esperanza de ir a Cuba cuasi todos han dejado las colocaciones que ocupaban [en Cataluña], contando muchos de ellos que en acabando allí la campaña encontrarán todos buenas colocaciones...», explicó uno de los promotores de la operación, en marzo de 1869, al futuro Ministro de Ultramar Víctor Balaguer [Garcia-Balañà 1995, 95 y 105]. La visión de Cuba como mercado de trabajo con expectativas de rápida promoción, antes que como destino mercenario, parece confirmada por un segundo dato: el 66\% de los casi 1.000 Voluntarios estudiados declararon, al alistarse, oficios urbanos de tradición artesana o industrial; apenas el 15\% dijeron ser campesinos o "jornaleros" sin más [Moreno Masó 1993, 53-78 y 69].

Todo ello debe ser comprendido a la luz de la diáspora catalana tejida en el Caribe español y sus fronteras desde los años 1810s-1820s, tras la refundación colonial de Cuba y Puerto Rico en respuesta a la crisis del imperio continental. Los catalanes tomaron claramente la delantera en la emigración metropolitana hacia Cuba en los años 1830s, y en 1860 su peso en la población peninsular de la isla (casi el 16\% de 70.000) aún superaba su peso en la población de la metrópoli (casi el 11\%) [Yáñez 1996, 52-54 y 83-90]. Más decisivos que los perfiles cuantitativos resultaron los cualitativos. Se trató de una emigración esencialmente masculina, de hombres jóvenes procedentes de la Cataluña litoral y urbana, con formación comercial o artesana, y con expectativas de promoción laboral y de retorno a 10 años vista o más. Una diáspora de redes familiares y cadenas migratorias activas o latentes, abastecidas regularmente con hermanos solteros, parientes o conocidos. Y una diáspora fundamentalmente comercial y de actividades urbanas asociadas, una red regional de apertura y explotación de nuevos flujos de comercio colonial y atlántico con epicentros en el Caribe español y en la notable industrialización catalana [Yáñez 1996, 56-70 y 169-209; Fradera 1987]. En 1843 el 33\% de los más de 1.300 “comerciantes” registrados 
en La Habana había nacido en Cataluña (y sólo el 11\% había nacido en la isla). Entre 1850 y 1865 el 65\% de los nuevos comerciantes metropolitanos registrados en Santiago de Cuba (donde los isleños también eran minoría) había nacido asimismo en Cataluña [Rodrigo Alharilla 2007, 21-23].

Sin embargo, esta potente conexión migratoria y social entre Cataluña y el Caribe español se debilitó significativamente durante los años 1870s y 1880s. Si durante el bienio 1860-1861 el 72\% de los emigrantes catalanes hacia las Américas se había trasladado a Cuba y Puerto Rico, durante los años 1885-1890 este porcentaje se redujo al 26\%. Argentina y Uruguay sumaron ya entonces casi el 60\% de toda la emigración catalana hacia el mundo atlántico americano [Yáñez 1994a, 264-266]. También estaban cambiando los perfiles sociológicos de dicha emigración: en 1889 las provincias catalanas abrumadoramente campesinas de Tarragona y Lleida sumaron el 24\% de los emigrantes (por sólo el 4,5\% en 1861), y los “agricultores” se dispararon entre los embarcados en el puerto de Barcelona [Yáñez 1994a, 257-258 y 275-280]. Aunque la tasa emigratoria catalana creció levemente entre 1860 y 1890, al iniciarse la última década del siglo se situó bastante por debajo de la tasa media española, muy al contrario que a principios de los años 1860 s [Yáñez 1994b, 241-250]. Los cambios detectados en la emigración catalana expresan una alteración decisiva del lugar de la Cuba colonial en el mapa de las expectativas metropolitanas y populares, en parte por la irrupción de nuevos destinos (ajenos al control político español) y de nuevas comunidades de emigrantes (más alejadas de las experiencias y culturas urbanas). De los aproximadamente 420.000 españoles que emigraron hacia las Américas entre 1880 y 1890, el mismo número, unos 160.000 o el 38\%, se dirigió hacia Cuba y ya hacia Argentina. En 1861-1862 Cuba había captado el 73\% de toda la emigración española hacia el Atlántico 5 .

5 Yáñez 1994b, 114-115 (Brasil fue el tercer destino entre 1880 y 1890, con casi 
La recolocación de la Cuba colonial como destino ya no exclusivo -o casi- de la emigración española no significó un estancamiento de los flujos migratorios hacia la isla; al contrario. Las aproximadamente 10.000 llegadas/año de los tempranos 1860s iban a fluctuar entre las 12.000 y las 20.000 llegadas/año durante los 1870 s y 1880 s (sin restar los numerosos retornos pero tampoco sumar las muy numerosas expediciones militares) [Yáñez 1994b, 42 y 48-51]. Lo que sí significó la nueva emigración de masas, combinada con las consecuencias de la Primera Guerra Cubana (1868-1878), fue la pérdida de centralidad del modelo diaspórico catalán de la etapa 1830s-1860s, así en La Habana como en Barcelona. La expectativa migratoria con garantía de colocación y probable promoción en un mercado de trabajo colonial múltiplemente segmentado (por la existencia de la esclavitud y otras formas de trabajo forzado, de una gran mayoría de blancos insulares y una influyente minoría de blancos peninsulares, de vínculos regionales que organizaban y jerarquizaban a estos últimos, etc...) iba a resultar más difícil de albergar durante la etapa final 1870s-1890s s. $^{6}$

Baste un ejemplo para ilustrar este punto. El quinquenio que se inició en 1886-1887 fue el de mayor movimiento emigratorio civil desde la metrópoli en la historia de la Cuba colonial. Los 14.000 emigrantes de 1886 se habían convertido en más de 28.000 en 1892, el año con mayor número de salidas de civiles hacia Cuba antes de la independencia [Yáñez 1994b, 48-49]. Hoy sabemos que muchos de estos emigrantes viajaron bajo el patrocinio de empresas para la inmigración vinculadas a grupos de hacendados en la isla; campesinos mayormente canarios y gallegos para trabajar en la cosecha del azúcar. Una emigración subsidiada por el Estado, bajo contrato encubierto y fundamentalmente estacional, concentrada en los meses invernales de la zafra cubana. A

39.000 llegadas) y 24-26. También Sánchez Alonso 1995, 281 y 284.

6 Una interpretación distinta de la nueva emigración de los 1870s-1890s, que sin embargo ha inspirado mi reflexión, en Fradera 2006, 520-524. 
menudo una "emigración golondrina", pues muchos iban y regresaban en el plazo de meses. En 1892 una sola de estas empresas, la Sociedad Protectora del Trabajo Español en las Posesiones de Ultramar, trasladó a más de 4.000 emigrantes, el 15\% del total anual [Balboa Navarro 2000, 227-229]. Podemos leer esta tardía emigración campesina y contratada como una evidencia del declive de España en el Caribe. Como una urgente respuesta a la desaparición de la esclavitud cubana en 1886, proceso inseparable de la rebelión criolla de 1868-1878 y su masiva dimensión negra; como una búsqueda simultánea, pues, de trabajadores agrarios, blancos y “españoles”. También como una pírrica victoria de los hacendados proespañoles, más interesados en la sobreabundancia estacional de hombres sin tierra que en la formación de una clase de colonos o potenciales propietarios. Pero podemos leerla, asimismo, como una de las razones, ella misma y sus causas y consecuencias, de que la Cuba colonial perdiera interés para una emigración de raíces urbanas y artesanas como la catalana. Recordar aquí que entre 1885 y 18906 de cada 10 pasajeros trasatlánticos por el puerto de Barcelona se dirigieron a la región del Río de la Plata, mientras que poco más de 2 de cada 10 fueron a Cuba. Precisamente en el Buenos Aires de los años 1880s y 1890 s, y entre esta creciente comunidad catalana, la investigación ha reencontrado algunos de los principales rasgos del modelo diaspórico catalán de mitad de siglo, en recesión en el Caribe. Orígenes urbanos y significativa cualificación profesional, cadenas migratorias siempre vivas pero nunca saturadas, redes laborales y asociativas en la gran ciudad (pero no en su hinterland rural), notable y pronta movilidad social ascendente entre los llegados antes de 1900, etc... [Moya 1998, 13-14, 60-68, 228-232 y 259-267]. El cónsul de Argentina en Barcelona lo había advertido en un informe de 1882, localizado y transcrito por Jose C. Moya [Moya 1998, 66]: "The push for Catalans is the desire to make fortunes rather than the need to placate hunger».

La masiva emigración metropolitana hacia territorios no imperiales no constituye, per se, un indicador de final del imperio. Los territorios de la 
Commonwealth e Imperio no concentraron a la mayoría de emigrantes de las Islas Británicas hasta la primera década del siglo XX [Constantine 1999, 165-167]. Lo que sí resulta llamativo - y opuesto a la experiencia británica de entonces - es que los emigrantes menos cualificados capitalizasen el destino imperial (campesinos y soldados de leva hacia la Cuba de los 1880 s y 1890s) mientras los más cualificados, y más influyentes en las ciudades metropolitanas, se redirigiesen hacia destinos ajenos al poder de Madrid (artesanos catalanes hacia la Argentina de los 1880s y 1890s). Este enfriamiento de determinadas expectativas imperiales fue, ante todo pero no únicamente, la consecuencia de una espiral de debilidades metropolitanas. Desde el colapso social y político del mercado de trabajo urbano en la Cuba de los 1880s [Casanovas 1998, 146-202], hasta la incapacidad para dar forma a algún tipo de destino imperial sustitutorio, por modesto que fuese, en los territorios africanos y asiáticos. La historia de la fracasada colonización civil de los territorios españoles del Golfo de Guinea, esbozada precisamente hacia 1860 pero ya absolutamente subrogada a la misión católica en los 1880s ante la amenaza del "Principle of Effectivity» sancionado en la Conferencia de Berlín (1884), ejemplifica esta segunda debilidad [García Cantús 2003, 343-564]. Los años 1880s y tempranos 1890s ejemplifican, pues, el crepúsculo de toda biopolítica imperial atractiva para las más dinámicas clases trabajadoras metropolitanas, desafiada la "rehispanización" en Cuba y raquítica y muy vigilada la expansión española en el norte y oeste de África. En 1900, mientras 24.000 españoles residían en los territorios norteafricanos y apenas 500 "blancos" en la isla hispano-guineana de Fernando Poo (por más de 18.000 "negros del continente" e indígenas bubis)', más de 200.000 españoles residían en la Argelia colonial francesa $(100.000$ recientemente naturalizados) adónde un mínimo de 300.000 habían

7 Territorios norteafricanos de Ceuta, Melilla, Alhucemas, Islas Chafarinas y Peñón de la Gomera, según el Censo Provincial de España de 1900. El censo de Fernando Poo (1901) - actual isla de Bioko en Guinea Ecuatorial - en García Cantús 2003, 564-566. 
emigrado desde 1882 [Sánchez Alonso 1995, 286-287].

\section{Crisis colonial y contrarrevolución metropolitana: de la pro- yección ultramarina de la Milicia Nacional al antimilitarismo popular}

El declive imperial español del último tercio del siglo XIX tuvo una enorme dimensión militar, así en las colonias como en la metrópoli. Durante la Primera Guerra Cubana (1868-1878) más de 175.000 hombres armados cruzaron el Atlántico, a los que pueden sumarse los Cuerpos de Voluntarios civiles en la Cuba proespañola, casi 60.000 hombres en 1871. Durante la guerra de 1895-1898 serían unos 220.000 los soldados transportados a Cuba, para un total de más de 500.000 durante las tres décadas 1868-1898 [Yáñez 1992, 110-114]. Pocas expediciones coloniales resisten para entonces la comparación cuantitativa, apenas los 450.000 hombres movilizados por el ejército imperial británico desde 1899 para la South African War. Las campañas militares en Marruecos antes del establecimiento del Protectorado español en 1912 no quedaron muy atrás en cuanto a volumen de tropas: más de 48.000 hombres cruzaron hacia Ceuta durante la Guerra de África de 1859-1860, y al finalizar la breve campaña de 1909 en el Rif los movilizados habían sido unos 42.000, de los cuales 20.000 permanecerían en África para ocupar parte del futuro Protectorado [Balfour 2002, 60-63]. Estos grandes contingentes, y sus pequeños resultados, pueden ser leídos como síntomas de la creciente debilidad ultramarina de Madrid a condición de no perder de vista las circunstancias metropolitanas que los hicieron posibles al tiempo que crecientemente ineficaces en términos militares y coloniales. De la comparación entre 1859/1869 y 1895/1909 en Barcelona parece desprenderse que algo cambió en la relación entre los reclutamientos armados para Ultramar y las expectativas populares sobre el imperio y sus bondades. Algo que, al igual que las expectativas 
de promoción a través de la migración imperial, era el resultado de una continua y cambiante alquimia entre crisis colonial y crisis metropolitana.

Lo que distinguió a los Voluntarios Catalanes de 1859-1860 y 1869 fue su singularidad con respecto a las tropas de "Quintos" o reclutas forzosos. Singularidad de su condición voluntaria, de las condiciones del enganche y del servicio, de la procedencia civil de sus mandos, de su indumentaria y de sus símbolos, incluso de sus posiciones en el frente de guerra (la defensa de la retaguardia lealista en la Cuba de 1869-1871). Para cualquier observador contemporáneo estas singularidades podían evocar varios significados, pero fundamentalmente uno: su indiscutible proximidad a la Milicia Nacional española de las décadas 1830s-1860s [Garcia-Balañà 2002, 27-50]. Hija de las movilizaciones populares durante la guerra contra Napoleón y durante las guerras civiles contra los absolutistas de los 1820 s y 1830 s, la Milicia Nacional fue uno de los campos de batalla donde se libró el pulso entre las distintas facciones del liberalismo español entre 1837 y 1876. Institución armada de defensa civil, organización urbana propicia a la politización de las masas, la Milicia inspiró muchos recelos en los liberales llamados Moderados (que la disolvieron en 1844, 1856 y 1874) y una variable simpatía en los liberales Progresistas (que la restablecieron en 1854 y 1868) y, sobre todo, en los más radicales Republicanos. Su existencia y su reivindicación alumbró, en la Cataluña urbana como en Madrid, toda una cultura política fundada en la camaradería armada entre civiles, en la autonomía respecto de un Ejército crecientemente corporativo y clasista, y en las expectativas de recompensas materiales y simbólicas con legitimación democratizadora. Un mundo de "redes milicianas" que contrastaba con el Ejército de leva redimible mediante pago al Estado [Garcia-Balañà 2008a; Garcia-Balañà 2014, 241-250]. A la luz de este cuadro metropolitano quizás resulte menos desconcertante el hecho de que, en abril de

8 Ver mi argumento con detalle en Garcia-Balañà 2002, 27-50. 
1869, la prensa Republicana celebrase a los Voluntarios Catalanes que marchaban a Cuba al tiempo que maldecía del Ejército de "Quintos” o reclutas forzosos (que también embarcaba para Cuba) 9 El éxito metropolitano y popular de los Voluntarios Catalanes en 18591860 y en 1869 resulta incomprensible sin tener en cuenta esta dimensión miliciana que los singularizó y les proporcionó visibilidad (muy por encima del peso de sus números) en el interior de ambos ejércitos coloniales. La evocación de aquel mundo civil y miliciano a través de los Voluntarios Catalanes llevó al más relevante opositor prorrepublicano al gobierno O'Donnell a publicar lo siguiente en la Barcelona de 1860:

La clase media y sobre todo las clases proletarias son las que han manifestado en esta ocasión mayor patriotismo... [...] Cuando [los neocatólicos] creían que la guerra contra los mahometanos reavivaría el muerto fanatismo, las antiguas tradiciones históricas que suponían favorables para sus intereses, los absolutistas modernos se han encontrado con el espíritu liberal tan íntimamente ligado al sentimiento de patriotismo, que no han podido menos que convencerse de que, y de hoy [en adelante] más, patria y libertad son sinónimos [Ventosa 1860, 129-130].

Si el imperialismo liberal alimentado por la Guerra de Crimea (18531856) dio alas a los Radicales británicos en su nada inocente apoyo a Garibaldi en Italia, mediante la llamada "British Legion", la Guerra de África y los activistas Republicanos próximos a los Voluntarios Catalanes alumbraron la más modesta "Legión Ibérica". Un centenar de Voluntarios regresados de Marruecos zarparon desde Barcelona rumbo a Génova en septiembre de 1860 [Garcia-Balañà 2002, 48-50; Pascual Sastre 2002, 347-376].

Estas conexiones políticas y sociológicas no se habían desvanecido en 1869, durante los primeros tiempos de los Voluntarios Catalanes en la guerra cubana. La prensa obrera de Barcelona celebró incluso su con-

9 «Lo Somatent. Periódich Polítich Lliberal»(17 de Abril de 1869), 2-3 (Son los Catalans, ja venen y, en el mismo número, jFora Quintas!). 
dición de hombres comunes armados en un escenario de inicial proliferación de Voluntarios civiles en la Cuba urbana y proespañola. En el verano de 1872 el periódico barcelonés La Federación, primera tribuna del sindicalismo obrero en la ciudad, publicó el siguiente argumento - mezcla de realidad y deseo - sobre las consecuencias de la guerra cubana en las jerarquías de la Cuba lealista o proespañola: «El obrero y el artesano español ocupaban a veces un puesto un poco más elevado que el negro; se les consideraba como un mal necesario. Los altos funcionarios, la pretendida nobleza y los orgullosos plantadores parecían mirarles con desdén y evitar su contacto. Todo esto ha cambiado mucho y cambiará todavía [...] porque el obrero posee ahora [en La Habana] un fusil»".

Un paisaje lealista donde la autoridad natural de las élites peninsulares y de los militares no iba a resultar ni plácida ni incontestada. Inés Roldán y Joan Casanovas han documentado, por ejemplo, los factores de división interna que sacudieron a los Cuerpos de Voluntarios en Cuba durante los años 1873 y 1874 . Cuando la vida breve de la Primera República española, en 1873, se hicieron más evidentes las simpatías republicanas de muchos Voluntarios de origen peninsular, trabajadores asalariados en las ciudades cubanas. Precisamente su participación en el llamado "servicio de armas" voluntario facilitó, desde 1869, la creación de sindicatos de oficio y sociedades de socorros mutuos entre la inmigración metropolitana. El proceso se intensificó en los primeros meses de 1873 con la fundación del Centro Nacional de Artesanos en La Habana, contrapunto obrerista y republicano al muy monárquico, conservador y elitista Casino Español, ambos sin embargo con representación en los batallones de Voluntarios. A finales de 1873 la tensión explotó en el interior de dichos batallones: mientras el Centro Nacional de Artesanos y muchos Voluntarios "de tropa" protestaban contra el

10 Isla de Cuba, "La Federación (Órgano de la Federación Barcelonesa de la AIT)», 157 (18 de Agosto de 1872), 4. 
desplome de los salarios reales en La Habana, motivado por la financiación inflacionaria de la guerra, el Casino Español, más influyente entre los oficiales de los batallones, perseguía la expulsión de los Voluntarios "republicanos" [Roldán de Montaud 1992; Casanovas 2000, 125-137]" Tras la caída de la República el nuevo Capitán General de Cuba, Joaquín Jovellar, tuvo que recurrir a la Guardia Civil, en marzo de 1874, para dispersar la manifestación de centenares de Voluntarios contra la movilización selectiva hacia las zonas de guerra del 10\% de los Voluntarios "de tropa”, liberados en cambio los oficiales. Jovellar había telegrafiado a Madrid sobre su desembarco en la Cuba proespañola: «Las clases superiores están sometidas, cosa que no ocurre con las inferiores» [Casanovas 2000, 136-137] ${ }^{12}$.

Simultánea y significativamente, la crisis trasatlántica inaugurada en el otoño de 1868 con la revolución antiborbónica que expulsó de España a la reina Isabel iba a significar el principio del fin de la Milicia Nacional. Durante el llamado Sexenio Democrático (1868-1874) la cuestión del derecho de los civiles a armarse en batallones urbanos cargó otra vez de tensión la vida política metropolitana; cuestión inseparable de la extensión del sufragio masculino y de las libertades de asociación y opinión. La región urbana de Barcelona fue, entonces al igual que durante las décadas de 1840 y 1850 , el principal teatro del conflicto. Multitudinarias manifestaciones contra el reclutamiento militar forzoso en la primavera de 1869 mientras se restablecía de facto la Milicia Nacional - rebautizada como Voluntarios de la Libertad - con abundante participación artesana y obrera; e inmediata presión gubernamental para controlar y reducir a dicha milicia civil, convertida en plataforma

11 Simpatías republicanas de los trabajadores emigrados recientemente desde la España europea: Biblioteca Museu Balaguer (Vilanova i la Geltrú, Barcelona), Correspondencia recibida por Víctor Balaguer, 7300381: carta de Ramón Vila a Víctor Balaguer (La Habana, 15 de Mayo de 1873). Sobre financiación fiduciaria de la guerra, escasez de moneda metálica e inflación en Cuba: Roldán de Montaud 1990, 88-106.

12 Otro episodio muy similar tuvo lugar en 1887: Casanovas 1995, 26-27. 
de acción y ampliación popular del Republicanismo temprano. La tensión estalló en el otoño de 1869 en forma de desigual combate urbano entre los batallones más plebeyos de la Milicia Nacional y el Ejército. Una lucha que se repetiría en otros puntos de la geografía peninsular, y que regresaría a Barcelona en 1870 y durante los pocos meses de vida de la Primera República española, en 1873 [Garcia-Balañà 2008b; Garcia-Balañà 2014]. El colapso del bloque Republicano durante 1873 daría paso a la restauración pretoriana en 1874 y a la de la monarquía borbónica - en la figura del joven Alfonso XII - en 1875. La restrictiva Constitución de 1876 liquidó para siempre la Milicia Nacional. Reveladoramente, el peso absoluto y relativo del Ejército de leva aumentó en Cuba desde 1876 - en detrimento de los Cuerpos de Voluntarios - en lo que iba a resultar la fase decisiva y final de la primera guerra [Yáñez 1992,110]. Todo ello mientras la nueva ley electoral de 1878 reducía el derecho de voto a poco más del 15\% de la población masculina mayor de 20 años (entre 800.000 y 950.000 electores entre 1879 y 1890), contra el sufragio universal masculino para la España europea que habían contemplado las constituciones de 1869 y 1873.

Con la Restauración borbónica en 1875-1876 regresó la “Quinta” con mayor carga clasista: reclutamientos provinciales de hombres en edad militar, del 20\% inicial (de ahí "Quinta") a más del 60\% con la coartada de la guerra colonial, mediante sorteo pero con opción a la redención en metálico o a la compra de "sustitutos". En verdad, un potencial y odiado impuesto indirecto, dado el uso del sobrerreclutamiento para paliar los apuros de la Hacienda metropolitana, agravados por el desafío cubano. Los 9 millones (de pesetas) de ingresos del Estado por redención en metálico del presupuesto 1894-1895 se convirtieron en 1895-1896tras el inicio de la Segunda Guerra Cubana - en 30 millones de ingresos efectivos, y en 42 millones durante 1896-1897 [Núñez Florencio 1990, 225]. Simultáneamente el Estado financió la guerra mediante la emisión monetaria e inflacionaria y, sobre todo, mediante deuda a tipos atractivos para los grandes inversores, deuda que a 31 de diciembre de 
1898 casi equivalía al PIB anual español [Pan-Montojo 2006, 292-294]. Este cuadro metropolitano de muy desiguales presiones fiscales se completaba, para las muchísimas familias que no podían hacer frente al pago de la redención militar (de hasta 2.500 pesetas, el equivalente al ingreso anual de una familia de trabajadores industriales cualificados en la Barcelona de fin de siglo), con la percepción de la "Quinta" como una “contribución de sangre". Y ello tenía mucho que ver con la naturaleza de la guerra colonial durante el declive imperial español de los años 1870s-1890s. En 1878 aproximadamente el 50\% de los más de 175.000 soldados trasladados a la Primera Guerra Cubana había muerto durante la campaña. Sin embargo, apenas el 10\% de aquéllos habían muerto en combate o a causa de éste; el 90\% habían muerto por fiebres y por las pobrísimas condiciones sanitarias y materiales del ejército expedicionario [Casanovas 2000, 55]. Durante el primer año de la Segunda Guerra, en 1895-1896, 4 de cada 5 "Quintos" muertos lo serían también por «enfermedades tropicales» [Pérez Ledesma 2006, 101]. Los costes domésticos de este tambaleante y escuálido militarismo colonial se repartirían según la correlación de fuerzas, políticas y sociales, impuesta por la contrarrevolución metropolitana de 1874-1876.

Las ocasionales demostraciones de patriotismo de masas en la España urbana de 1895 o 1898 - o en 1885 cuando la disputa con Alemania por la soberanía sobre las Islas Carolinas en el Pacífico - no deben oscurecer lo fundamental del cambio histórico con respecto a los tempranos 1860s. A saber, que ya antes de 1895 las políticas metropolitanas que se proyectaban sobre el Ultramar colonial y sus fronteras habían pasado a alimentar más agravios que expectativas entre los sectores populares, cuando menos en lugares como la Barcelona metropolitana. Tales agravios nacían de una muy concreta combinación entre declive o debilidad imperial y contrarrevolución metropolitana, y podían resultar más dolorosos por oposición a las oportunidades migratorias y milicianas en Ultramar - y a sus feedbacks metropolitanos - de la generación de mitad de siglo. 
Dos fragmentos de la historia metropolitana de las guerras de 18951898 permiten ilustrar la profundidad de este cambio. En el terreno de las culturas políticas radicales, la cuestión del reclutamiento desigual y elevada mortalidad de la guerra cubana obligó a muchos líderes Republicanos a reformular su firmeza patriótica y antiseparatista, sin abandonarla, y a reclamar ya en el verano de 1896 «QQue vayan todos, pobres y ricos!». Sin embargo, esta crítica desde el interior del patriotismo liberal-radical y mesocrático allanó el camino para la definitiva irrupción de nuevos actores políticos metropolitanos, indiscutiblemente antimilitaristas y antiimperialistas. Los Socialistas del jovencísimo PSOE (Partido Socialista Obrero Español), quienes apenas habían sumado 14.000 votos en las elecciones de 1896, reunieron a más de 100.000 personas en su campaña de 1897 bajo el lema « $\mathrm{O}$ todos o ninguno!», que en realidad clamaba por lo segundo (a diferencia del lema Republicano) [Serrano 1984, 99-112; Pérez Ledesma 2006, 114-116 y 123]. Simultáneamente, confluían en Barcelona el creciente activismo anarquista autóctono y las redes europeas de apoyo a los nacionalistas cubanos, puertorriqueños e incluso filipinos. Una historia de "anarquismo e imaginación anticolonial" que Ben Anderson ha contado a partir del forzado encuentro en la prisión barcelonesa de Montjuïc, en el otoño de 1896, del líder filipino José Rizal, del expatriado cubano de padre catalán Fernando Tarrida del Mármol (pronto uno de los hombres de Martí y Betances en Europa), y de los anarquistas locales allí detenidos y torturados [Anderson 2005, 169-195].

Si las culturas políticas de masas estaban cambiando, alejándose del Estado y su política colonial, las experiencias populares del día a día de dicha política anticipaban ya la España posimperial. Baste el ejemplo de la resistencia popular al reclutamiento militar para la última guerra cubana. Los prófugos y desertores se doblaron entre 1895 y 1898 (del 2,5\% al $5 \%$ del contingente de alistados), pero su impacto se disparó sobre todo en las regiones marítimas y fronterizas del norte (en Galicia rozaron el 14\%) y del este, Cataluña entre ellas. La razón estriba, por supuesto, 
en la mayor facilidad para la huída a territorio extranjero desde dichas regiones. Un refugio extranjero que se hallaba en la Francia del primer exilio anarquista pero, sobre todo y significativamente, en las repúblicas latinoamericanas destinatarias desde los años 1880s de las nuevas y más dinámicas comunidades de emigrantes peninsulares españoles [Serrano 1984, 92-99; 1982].

\section{Civilización, raza y política en la Barcelona ultramarina: ex- pectativas y desencantos imperiales (de 1860 a 1893)}

C. A. Bayly ha recordado la dificultad de explicar la veloz expansión imperialista del periodo 1870-1914 sin tener muy en cuenta la simultánea aceleración del proceso de nation-building en las sociedades metropolitanas (y en las mismas sociedades coloniales). Las nuevas funciones del Estado, y las nuevas lealtades movilizadas por su naturaleza "nacional", contribuyeron decisivamente a la acción imperial, mediante un doble juego de renovadas unanimidades intranacionales y renovadas rivalidades internacionales [Bayly 2004, 228-233]. Por su parte, Catherine Hall, Antoinette Burton y otros han sintetizado sus definitivos trabajos sobre la complejidad y fluidez de aquellas unanimidades en las sociedades británicas de las décadas anteriores a la Gran Guerra, sobre la maleabilidad social y polisemia política de los lenguajes civilizatorios asociados a la reconfiguración y expansión del Imperio desde los 1860 s. Estos lenguajes de jerarquización cultural, racial y de género, y con ellos las expectativas imperiales que los cargaban de sentidos, resultaron determinantes, por ejemplo, en la reclamación y legitimación de las reformas democratizadoras en la metrópoli (1867 y 1884-1885) y en los White Dominions [Hall, Rose 2006].

Lo singular del caso español no fue sólo la demostración de fuerzas, propias y prestadas, de sus jóvenes nacionalismos anticoloniales, el cubano ante todo. Lo fue, también, la enorme dificultad para activar, a 
modo de réplica, alguna de aquellas unanimidades o alianzas metropolitanas e interclasistas. Después de 1868-1874 toda crisis colonial amenazó con una mayor crisis metropolitana, por la magnitud del desafío declarado en la España caribeña pero, asimismo, por la magnitud de las expectativas "nacionales" - por más comunes - defraudadas en la España europea, también de aquellas que miraban hacia Ultramar.

En 1860 otra de las fuentes de legitimación popular de los Voluntarios Catalanes había sido su contribución a la guerra de expansión contra los marroquíes, «esa raza de esclavos» en palabras - cantadas - del músicoobrero y líder Republicano Josep A. Clavé. Al combatir a una "raza de esclavos", es decir, a unas gentes que arrastraban la exclusión política y civil inscrita en el código genético, los Voluntarios combatían a su vez contra los peores fantasmas de cierta Barcelona interclasista y radicaldemocrática, la misma que había sido desarmada en 1856 y perseguida durante los dos años siguientes. Una de las comparsas africanistas del Carnaval barcelonés de 1860 lo expresó con discreta contundencia: en ella la caricatura del sultán marroquí iba de la mano de la sátira de Ramón M. Narváez, el militar y líder del Partido Moderado español, artífice de las reacciones conservadoras y restrictivas de derechos políticos de 1844-1845 y 1856-1857. El déspota marroquí era la réplica, lejana y exótica, de un déspota autóctono más familiar y peligroso. Su imagen especular [Garcia-Balañà 2002, 36-39, 45-48 y 58-63]. Estas afirmaciones de orgullo político plebeyo, por oposición a un inferior racial y social ultramarino, reaparecieron en 1869 a propósito de los Voluntarios dirigiéndose al combate contra la Cuba de la rebelión criolla pero sobre todo africana [Garcia-Balañà 1995, 93 y 94-102]. Ambos casos traen a la memoria los trabajos de Catherine Hall sobre la noción de Englishmen acuñada por John Bright y sus clubs radicales obreros en la Inglaterra en camino hacia la Ley de Reforma Electoral de 1867. Su reclamación del derecho de voto para una significativa fracción de trabajadores manuales metropolitanos bebió de la experiencia imperial. Por ejemplo, de los renovados prejuicios raciales que recorrieron 
ciudades como Birmingham tras la rebelión negra de Morant Bay en la Jamaica de 1865. Según Bright lo fundamental para la extensión del gobierno representativo, y del derecho de voto, era la preeminencia demográfica de los «Englishmen with Saxon qualities». Al modo de un espejo invertido, ni la correlación racial ni el paisaje social jamaicanos favorecían las virtudes de "independence» (económica y comunitaria) de su «intelligent and honest working man» metropolitano, que así lo era, en gran parte, por oposición a la imprevisible rebeldía negra [Hall 2002, 380-433 y 424-426].

El optimismo ultramarino del radicalismo político barcelonés en los tempranos 1860s había mutado una generación después, antes de 1895, en pesimismo imperial, en lamentación sin embargo imperialista. La esperanza Republicana en obtener dividendos de la política colonial sobre poblaciones africanas se había desvanecido ya en la Barcelona de 1893. Entonces, y con motivo de una operación de castigo contra las tribus del norte marroquí, la muy enfática "Guerra de Margallo" (Octubre de 1893 - Abril de 1894), la prensa Republicana rememoró el episodio de 1859-1860. Pero rápidamente constató la frialdad patriótica de sus lectores, y la absoluta frialdad ciudadana ante el embarque de la artillería [Garcia Olivé 2008, 26-32]. Las dificultades militares del Ejército de leva (con escasa presencia de catalanes), y la pública vigilancia de la Alemania imperial sobre la operación (lo que subrayaba los mínimos frutos de la llamada "penetración pacífica" española en Marruecos desde los 1860s), provocaron juegos de imágenes imperiales antagónicos a los de 1859-1860. En diciembre de 1893 uno de los editores del gran periódico del Republicanismo barcelonés, El Diluvio, escribió y publicó [citado en Garcia Olivé 2008, 35]: «El pueblo [marroquí] con quien peleamos en 1860 está tan atrasado, tan petrificado en su desarrollo, como en aquella época gloriosa de nuestra vida, lo que es acusación para nuestra actividad, para nuestra inercia. El imperio no vive, el imperio no es más que una sombra, el imperio no es una unidad social». 


\section{Reference List}

Anderson B. 2005, Under Three Flags. Anarchism and the Anti-Colonial Imagination, London: Verso.

Balboa Navarro I. 2000, Los brazos necesarios. Inmigración, colonización y trabajo libre en Cuba, 1878-1898, Valencia: Biblioteca Historia Social.

Balfour S. 1997, The End of the Spanish Empire, 1898-1923, Oxford: Clarendon Press.

--- 2002, Abrazo mortal. De la guerra colonial a la Guerra Civil en España y Marruecos (1909-1936), Barcelona: Península.

Bayly C. A. 2004, The Birth of the Modern World, 1780-1914. Global Connections and Comparisons, Oxford: Blackwell.

Casanovas J. 1995, Movimiento obrero y lucha anticolonial en Cuba después de la abolición de la esclavitud, "Boletín Americanista», 45: 23-41.

--- 1998, Bread, or Bullets! Urban Labor and Spanish Colonialism in Cuba, 18501898, Pittsburgh: University of Pittsburgh Press.

--- 2000, ¡O pan, o plomo! Los trabajadores urbanos y el colonialismo español en Cuba, 1850-1898, Madrid: Siglo XXI.

Constantine S. 1999, Migrants and Settlers, in Brown J. M., Louis W. R. (eds.) 1999, The Oxford History of the British Empire. Vol. IV: The Twentieth Century, Oxford: Oxford University Press, 163-187.

Fradera J. M. 1987, Indústria i mercat. Les bases comercials de la industrialització catalana moderna (1814-1845), Barcelona: Crítica.

--- 2006, Las fronteras de la nación y el ocaso de la expansión hispánica, in PanMontojo J. (ed.) 2006, Más se perdió en Cuba. España, 1898 y la crisis de fin de siglo, Madrid: Alianza Editorial, 2a ed., 483-557.

Garcia-Balañà A. 1995, Tradició liberal i política colonial a Catalunya. Mig segle de temptatives i limitacions (1822-1872), in Fradera J. M. et al. 1995, Catalunya i Ultramar. Poder i negoci a les colònies espanyoles (1750-1914), Barcelona: Museu Marítim, 77-106.

--- 2002, Patria, plebe y política en la España isabelina: la Guerra de África en Cataluña (1859-1860), in Martín Corrales E. (ed.) 2002, Marruecos y el colonialismo español (1859-1912), Barcelona: Edicions Bellaterra, 13-77.

--- 2008a, Significados de República. Insurrecciones federales, redes milicianas y conflictos laborales en la Cataluña de 1869, «Ayer», 71 (3): 213-243.

--- 2008b, 'Ya no existe Partido Progresista en Barcelona'. Experiencia social y protesta obrera en la insurrección republicana de 1869, «HISPANIA Revista Española de Historia», 230: 735-760.

--- 2014, 'El verdadero productor'. Lenguaje y experiencia en la formación de las 
culturas políticas obreras, in Romeo M. C., Sierra M. (eds.) 2014, Historia de las culturas políticas en España y América Latina. Vol. II: La España liberal, 1833-1874, Madrid -Zaragoza: Marcial Pons Historia-PUZ, 217-252.

García Cantús M. D. 2003, Fernando Poo: una aventura colonial española en el África occidental, 1778-1900, Tesis Doctoral: Universitat de València.

Garcia Olivé X. 2008, 'Moros de dos menas'. Republicanismes barcelonins i la "Guerra de Margallo" (1893), Tesis de Máster inédita: Universitat Pompeu Fabra (Barcelona).

Hall C. 2002, Civilising Subjects. Metropole and Colony in the English Imagination, 1830-1867, Chicago-London: The University of Chicago Press.

Hall C., Rose S. O. (eds.) 2006, At Home with the Empire. Metropolitan Culture and the Imperial World, Cambridge: Cambridge University Press.

Hardman F. 1860, The Spanish Campaign in Morocco, Edinburgh-London: William Blackwood.

Moreno Masó J. J. 1993, La petjada dels catalans a Cuba, Barcelona: Comissió Amèrica i Catalunya.

Moya J. C. 1998, Cousins and Strangers. Spanish Immigrants in Buenos Aires, 18501930, Berkeley: University of California Press.

Núñez Florencio R. 1990, Militarismo y antimilitarismo en España (1888-1906), Madrid: Consejo Superior de Investigaciones Científicas.

Pan-Montojo J. 2006, El atraso económico y la regeneración, in Pan-Montojo J. (eds.) 2006, Más se perdió en Cuba. España, 1898 y la crisis de fin de siglo, Madrid: Alianza Editorial, $2^{\mathrm{a}}$ ed., 267-340.

Pascual Sastre M. I. 2002, La Italia del Risorgimento y la España del Sexenio Democrático (1868-1874), Madrid: Consejo Superior de Investigaciones Científicas.

Paz Sánchez M. de 2008, Martí, España y la masonería, Santa Cruz de Tenerife: Ediciones Idea.

Pérez Ledesma M. 2006, La sociedad española, la guerra y la derrota, en Pan-Montojo J. (ed.) 2006, Más se perdió en Cuba. España, 1898 y la crisis de fin de siglo, Madrid: Alianza Editorial, $2^{\mathrm{a}}$ ed., 97-155.

Rodrigo Alharilla M. 2007, Indians a Catalunya: capitals cubans en l'economia catalana, Barcelona: Fundació Noguera.

Roldán de Montaud I. 1990, La Hacienda en Cuba durante la Guerra de los Diez Años (1868-1880), Madrid: ICI/IEF.

--- 1992, La Primera República y Cuba, «Revista Complutense de Historia de América», 18: 257-279.

Sánchez Alonso B. 1995, Las causas de la emigración española, 1880-1930, Madrid: Alianza Editorial. 
Serrano C. 1982, Prófugos y desertores en la Guerra de Cuba, «Estudios de Historia Social», 22-23: 253-278.

--- 1984, Final del Imperio. España 1895-1898, Madrid: Siglo XXI.

Ullman J. C. 1968, The Tragic Week. A Study of Anticlericalism in Spain, 18751912, Cambridge: Harvard University Press.

Ventosa E. (Fernando Garrido) 1860, La regeneración de España, Barcelona: Librería de Salvador Manero.

Yáñez C. 1992, La última invasión armada. Los contingentes militares españoles a las guerras de Cuba, Siglo XIX, «Revista de Indias», 194: 107-127.

--- 1994a, Saltar con red. La emigración catalana a América, 1830-1930, Tesis Doctoral: Universitat Autònoma de Barcelona.

--- 1994b, La emigración española a América (Siglos XIX y XX), Colombres: Archivo de Indianos.

--- 1996, Saltar con red. La temprana emigración catalana a América (1830-1870), Madrid: Alianza Editorial. 